Research Article

\title{
Investigation of Silane Impregnation for Protection of Alkali-Activated Slag Mortar
}

\author{
Jin Li $\mathbb{D}^{D}$, Peiyuan Chen $(\mathbb{D}$, Haibing Cai $\mathbb{D}$, Ying Xu $\mathbb{D}$, and Murodjon Rasulov \\ School of Civil Engineering and Architecture, Anhui University of Science and Technology, Huainan 232001, China \\ Correspondence should be addressed to Peiyuan Chen; peiyuan29@126.com
}

Received 30 March 2021; Revised 1 August 2021; Accepted 18 August 2021; Published 29 August 2021

Academic Editor: Yuanshi Li

Copyright $\odot 2021$ Jin Li et al. This is an open access article distributed under the Creative Commons Attribution License, which permits unrestricted use, distribution, and reproduction in any medium, provided the original work is properly cited.

\begin{abstract}
This paper investigated the effects of silane impregnation on the protective properties of alkali-activated slag (AAS) mortars. The surface silane impregnation on water absorption, contact angle, and penetration depth were examined. The related protective mechanism regarding silane impregnation was analyzed by scanning electron microscope (SEM), X-ray diffraction (XRD), and Fourier infrared spectroscopy (FT-IR). The results showed that the surface of the AAS mortar after silane impregnation was transformed from hydrophilic to hydrophobic with an increased contact angle of $80^{\circ}$ from $36^{\circ}$ to $116^{\circ}$. And the water absorption was significantly decreased by $74.42 \%$ to $97.79 \%$. The penetration depth of the two-layer coating was dramatically higher than that of the one-layer coating. The optimal coating method and dosage of silane were two-layer coating and $200 \mathrm{~g} / \mathrm{m}^{2}$. In addition, silane impregnation formed a stable Si-O bond with AAS mortars through a hydrolytic condensation reaction and the $-\mathrm{CH}_{2} \mathrm{CH}_{3}$ group of the silane acted on the surface of the AAS mortars.
\end{abstract}

\section{Introduction}

The characteristics of AAS, such as easy preparation, low energy consumption, solid waste utilization, and low cost, have made it known as an environmentally friendly "green material" in the past few decades, with great development potential $[1,2]$. It is often considered as a potential alternative to ordinary Portland cement (OPC) with many advantages, such as superior compressive strength, resistance to acid and alkali erosion, freeze-thaw resistance, and carbonation resistance, which can effectively reduce carbon footprint and treat solid waste resources [3].

Although AAS has better performance than OPC, it is also commonly hydrophilic and porous [4-6]. When AAS material is exposed to the external aggressive environment for a long time, it is also vulnerable to the intrusion of aggressive substances, resulting in structural deterioration [7]. Consequently, the durability of AAS materials has to be widely concerned to make it better applied to the construction field. It is worthwhile mentioning that surface treatment is effective in improving the durability of cementbased materials [8].
There are three types of surface treatment that can be categorized: (1) sealing, which blocks the pores of concrete with a sealer; (2) surface coating, which applies a polymer film to form a continuous physical protective barrier on the concrete surface; and (3) surface impregnation, whereby a hydrophobic agent (silane or siloxane) is impregnated on the surface of the substrate, yielding a hydrophobic layer $[9,10]$. Many researchers have proved that the silane impregnation technology can establish a protective barrier on the concrete surface, enhance the durability of the concrete, and make the concrete breathe freely without loss of mechanical properties. However, the surface coating and sealing usually affect the permeability of concrete and the performance of the matrix $[8,11-14]$. In light of this, surface impregnation has been increasingly popular.

At present, research on the performance of surface impregnation on AAS mortar is limited. The main research is focused on the protective performance of surface impregnated concrete. Back in the 1980s, the influence of silane hydrophobic agent impregnation on the durability of concrete has been extensively investigated [15]. Many experiments have verified that surface impregnation with silane- 
based water repellent yields a hydrophobic film on the concrete surface, which can delay the corrosion of reinforced concrete. Evidence from extensive test results showed that silane dramatically reduced water absorption, internal humidity, and chloride ion penetration of concrete. Another research reported that concrete treated with ethyl silicate not only effectively enhanced the resistance to chloride ions and carbonation, but also left the pores open [14]. Furthermore, concrete beams treated with silane were still protective after 20 years of service, according to the results of Christodoulou [16]. Zhu et al. observed that the capillary water absorption of concrete was effectively improved by surface silane treatment with octyltriethoxysilane/siloxane and the penetration depth of silane on concrete under oven dried was between 6.8 and $9.1 \mathrm{~mm}$ [17]. Medeiros et al. showed that surface protection (such as hydrophobic agents, polyurethane coating, acrylic coating, and double systems) significantly reduced the sorptivity of concrete (reduction rate $>70 \%$ ) and the chloride diffusion coefficient (reduction rate of $86 \%)$ [18].

However, despite extensive previous researches focus on surface impregnation of cement-based materials by silanebased water repellents, there has been very limited work performed on the protection of silane impregnation on AAS mortars [16, 19-24]. It remains unknown whether such a surface impregnation is applicable for protection of AAS mortars. Moreover, previous researches on surface impregnation mainly studied the durability of carbonization resistance and chloride ion resistance and rarely analyzed it from the microscopic perspective. Therefore, there is a need to conduct a systematic experimental investigation to evaluate the protection of silane impregnation on AAS mortars and provide reference for the protection of AAS mortars. The objective of this paper is to study the protection of silane impregnation on AAS mortar. The isobutyltriethoxysilane was used, and three different dosages $\left(100,200\right.$, and $\left.300 \mathrm{~g} / \mathrm{m}^{2}\right)$ with two different coating methods (one-layer coating and two-layer coating) of silane were utilized to coat the surface of the AAS mortars. Water absorption, contact angle, and penetration depth of the silane of the AAS mortar were mainly evaluated. And samples of AAS mortars at the age of 28 days treated with silane or without silane were analyzed by SEM, XRD, and FT-IR to attain an in-depth understanding of the surface impregnation of silane on AAS mortars.

\section{Material and Method}

2.1. Materials. The Ground Granulated Blast Furnace Slag (GGBFS) was purchased from China Fuyang Xinyuan Building Materials Co., Ltd. And it is classified into S105 grade with an activity index greater than 105 according to GB/T 18046 [25]. Its apparent density and specific surface area of GGBFS are $2.8 \mathrm{~g} / \mathrm{cm}^{3}$ and $1.535 \mathrm{~m}^{2} / \mathrm{g}$, respectively. The chemical composition of GGBFS is shown in Table 1. Figure 1 shows the XRD pattern of the GGBFS at $2 \theta=10^{\circ}-70^{\circ}$. It can be clearly seen that the main component of GGBFS is melilite. The particle size distribution of GGBFS measured by a laser particle size analyzer is shown in Figure 2. Sand is used as the natural sand of
TABLe 1: Chemical composition of GGBFS.

\begin{tabular}{lccccccc}
\hline & \multicolumn{7}{c}{ Chemical composition/wt. \% (XRF) } \\
& $\mathrm{CaO}$ & $\mathrm{SiO}_{2}$ & $\mathrm{Al}_{2} \mathrm{O}_{3}$ & $\mathrm{MgO}$ & $\mathrm{Fe}_{2} \mathrm{O}_{3}$ & $\mathrm{TiO}_{2}$ & $\mathrm{~K}_{2} \mathrm{O}$ \\
\hline GGBFS & 43.7 & 26.5 & 18.2 & 4.9 & 1.0 & 1.0 & 0.8 \\
\hline
\end{tabular}

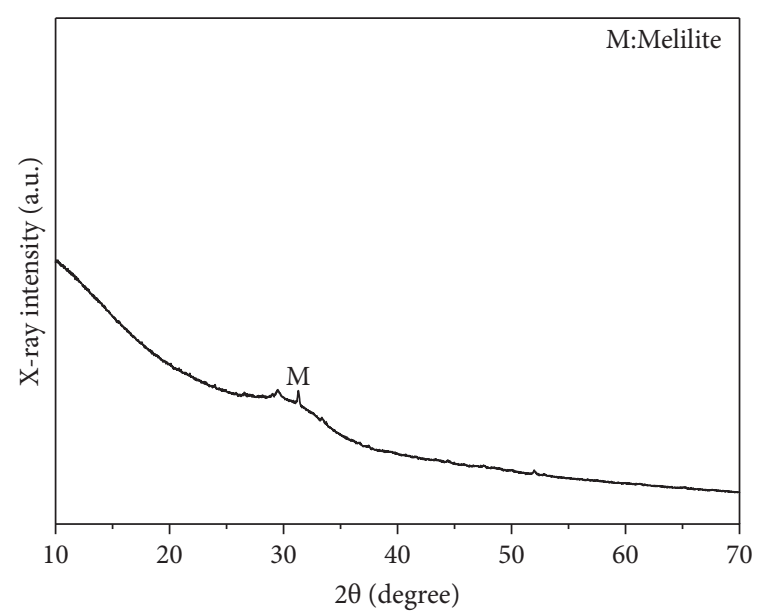

FIgURE 1: XRD pattern of GGBFS.

the Huai river in Huainan with a fineness modulus of 2.36 and an apparent density of $2600 \mathrm{~kg} / \mathrm{m}^{3}$. Tap water was used in the experiment. The silane impregnant produced by Beijing Mengtai Weiye Co., Ltd., was used. Its active ingredient was isobutyltriethoxysilane with a purity of $98.9 \%$, and its structural formula is shown in Figure 3. It can be seen that silane has three hydrolysable ethoxy groups and one isobutyl group. The hydrolysis time of silane can be tested by monitoring its conductivity [26]. The test solution was a $5 \%$ silane solution prepared in a mixture of distilled water. The hydrolysis time is determined at 26.5 hours by the maximum conductivity reached using a model DDSJ-308F conductivity tester (Shanghai INESA Scientific Instrument Co., Ltd., China), because the condensation reaction takes over along with the conductivity decreases. Figure 4 depicts the variation of the conductivity of the isobutyltriethoxysilane solution in time. The properties of the silane are indicated in Table 2. Granular sodium hydroxide of analytical purity with a content greater than $96.0 \%$ was purchased from Tianjin Hengxing Chemical Reagent Co., Ltd. Alkaline-activating solutions of the desired composition were formulated using $7 \mathrm{M}$ sodium hydroxide solution.

2.2. Preparation of Mortars and Coating Methods. For all mixtures, the mass ratio of the activator to GGBFS was kept at 0.5 , and the sand content was $45 \%$. Firstly, the dry experimental materials were put in a mixer for mixing for 3 minutes. Then, alkaline-activating solutions were poured into the mixer for another 2 minutes.

According to the Chinese standard JTJ 275-2000 [27], $40 \mathrm{~mm} \times 40 \mathrm{~mm} \times 160 \mathrm{~mm}$ prism specimens were cast and cured for 28 days under the standard conditions of $23^{\circ} \mathrm{C}$ and $\mathrm{RH}>95 \%$. Then, all specimens, after being taken out and cleaned, were dried in an oven at $60^{\circ} \mathrm{C}$ for 5 hours. The 


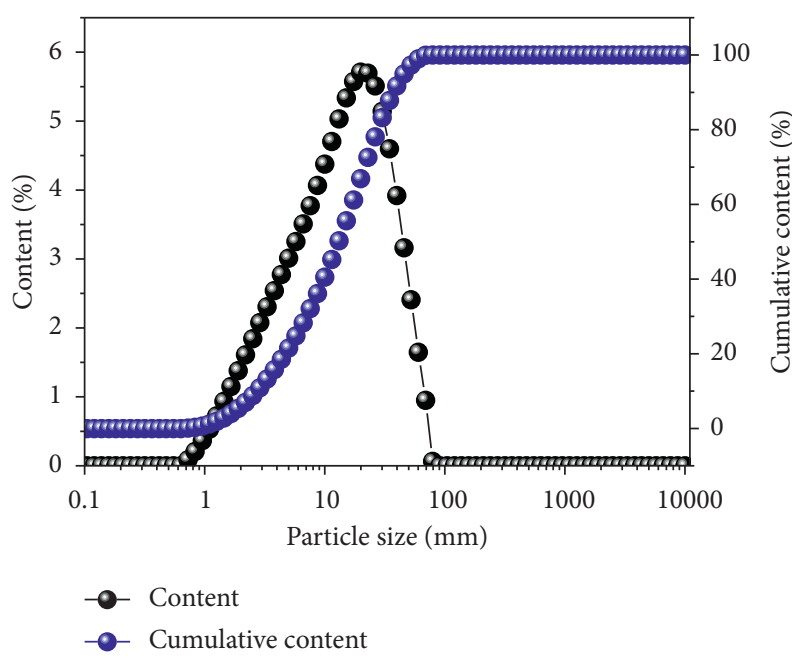

Figure 2: Particle size distribution of GGBFS.

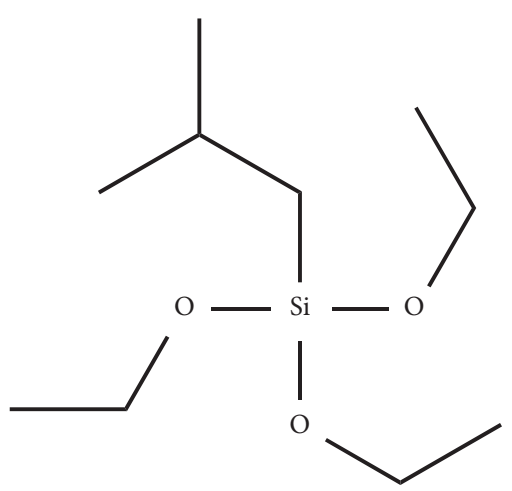

Figure 3: Structural formula of silane.

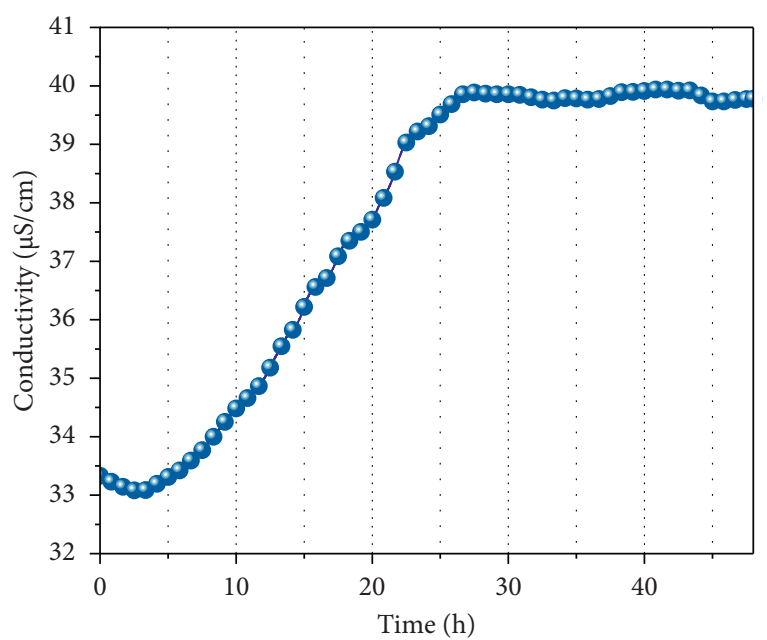

FIgURE 4: The variation of the conductivity of the silane solution in time.

remaining 5 surfaces of the specimen were sealed with paraffin except for one rectangular surface for testing. And the residual unsealed surfaces of the specimen were brushed with silane and were evenly brushed in the same direction for 8-10 times. Each brushing was conducted after the previous brushing was fully absorbed by the mortar. Three types of coating amounts of silane were selected for the experiment by two types of coating methods (one-layer coating and two-layer coating) using a brush. The time interval between two-layer coatings was 6 hours to ensure that the silane applied in the first-layer coating was fully bonded to the mortar. Table 3 provides a detailed coating scheme. For the codes of these mixtures, $\mathrm{C}$ indicates control group that uncoated AAS mortar, $\mathrm{O}$ indicates AAS mortar treated with one-layer coating, $\mathrm{T}$ indicates AAS mortar treated with two-layer coating, and the numbers following the letter identification indicate the coating dosage of silane. All test pieces were placed in a room temperature and windless environment to cure for 7 days after coating the specimens. Consequently, the relevant tests were carried out.

\subsection{Test Method}

2.3.1. Water Absorption. According to the Chinese standard JTJ 275-2000 [27], specimens cured for 7 days with silane coating were dried in an oven at $40^{\circ} \mathrm{C}$ for 48 hours. Then, the mass of specimens at $0,5,10,30,60,120$, and 140 minutes were tested according to the test method shown in Figure 5 [28]. Specimens were taken out for weighting and replaced immediately at each test until the end of the test. The calculation of water absorption height is shown in the following formula:

$$
H=\frac{\left(m_{t}-m_{0}\right)}{\rho} \times S,
$$

where $H$ is the water absorption height (unit: $m m$ ); $m_{\mathrm{t}}$ is the mass of the specimen at the corresponding testing time (unit: $\mathrm{g}$ ); $m_{0}$ is the original mass (unit: $\mathrm{g}$ ); $\rho$ is the density of water (unit: $\mathrm{g} / \mathrm{mm}^{2}$ ); and $S$ is the contact area between the mortar sample and water (unit: $\mathrm{mm}^{2}$ ). The water absorption rate was determined from the slope of the best fit line on the plot of the water absorption height against the square root of time.

2.3.2. Penetration Depth. The hydrophobic indicator method was used to test the penetration depth of silane. Samples cured for 7 days after silane coating treatment were broken by the bending resistance tester and then dried in a constant temperature drying oven at $60^{\circ} \mathrm{C}$ for 24 hours. Afterwards, water was sprayed onto the fracture surface of the test block as a hydrophobic indicator. The measurement of the depth of the area not wetted by water is the penetration depth of silane due to its hydrophobic property. 8-10 different locations were taken for measurement for each test specimen, and the average value was reported.

2.3.3. Contact Angle. To investigate the protective effect of coating methods and coating dosages on AAS mortars, the contact angle of the mortar surface was measured by a contact angle measuring instrument to characterize the hydrophobic performance of the AAS mortar. The water droplet size of each test was controlled within $3 \mu \mathrm{L}$, and the average value of three measurements was reported as the result. 
TABle 2: Properties of silane.

\begin{tabular}{lcccc}
\hline Product & Appearance & Active ingredient & Active ingredient content $(\%)$ & Specific gravity $\left(\mathrm{g} / \mathrm{cm}^{3}\right)$ \\
\hline Silane & Liquid white & Isobutyltriethoxysilane & $\geq 98.9$ & 0.88 \\
\hline
\end{tabular}

TABle 3: Coating method.

\begin{tabular}{lccc}
\hline Sample number & Total amount of coating $\left(\mathrm{g} / \mathrm{m}^{2}\right)$ & Once coating amount $\left(\mathrm{g} / \mathrm{m}^{2}\right)$ & Coating interval time $($ hours $)$ \\
\hline C & 0 & 0 & 0 \\
O100 & 100 & 100 & 0 \\
O200 & 200 & 200 & 0 \\
O300 & 300 & 300 & 0 \\
T100 & 100 & 50 & 6 \\
T200 & 200 & 100 & 6 \\
T300 & 300 & 150 & 6 \\
\hline
\end{tabular}

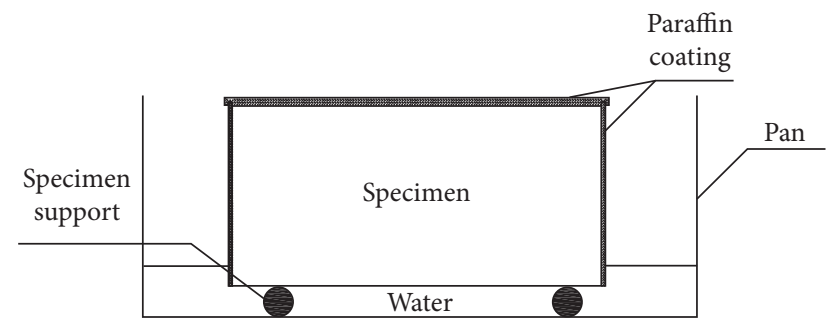

FIgURE 5: Schematic of water absorption test [28].

2.3.4. Microscopic Testing and Characterization of Mortars. Samples with and without silane coating were selected for microscopic testing. The micromorphology of each group was observed by SEM under a $10 \mathrm{kV}$ accelerating voltage. The samples were collected at a depth of 1-3 $\mathrm{mm}$ on the test surface and vacuum-dried. Before SEM observation, all the samples were sprayed with gold for 120 seconds to obtain better electrical conductivity.

The mineral phase composition of the sample was analyzed by $\mathrm{XRD}$ with $\mathrm{Cu} \_\mathrm{Ka}$ radiation. And its scanning angle and scanning speed were $5^{\circ}-85^{\circ}$ and $3^{\circ} / \mathrm{min}$, respectively. FTIR was used to further characterize the chemical functional groups of AAS mortar coated with different dosage of silane and different coating methods. And its infrared wavelength was $4000 \mathrm{~cm}^{-1}-400 \mathrm{~cm}^{-1}$. The spectra of all AAS mortar samples are documented according to the following detailed procedures: First, a specimen with a depth of $1-3 \mathrm{~mm}$ inside the test surface, taken from the prism which was cured for 7 days after coating, was vacuum-dried and ground to powder with a size of less than $75 \mu \mathrm{m}$. After the test, the Jade software and the Omnic software were employed to analyze the XRD and the FT-IR of the AAS mortar with and without silane coating, respectively.

\section{Results and Discussion}

3.1. Water Absorption. Water absorption is one of the main factors affecting the durability of AAS materials. Surface protective treatment can effectively reduce the water absorption property of materials, thereby improving the durability of the material. To investigate the protective effect of silane impregnation on AAS mortar, a water absorption test was carried out. Figures 6 and 7 show the water absorption height and water absorption of AAS mortars under different coating methods and different coating dosages, respectively. A similar regular is illustrated in Figures 6 and 7. As revealed by Figure 6, the water absorption height of AAS mortars without silane protection treatment was higher than surface impregnated mortars, indicating that AAS mortars were vulnerable to invasion by aggressive ions. Through surface impregnation by silane, the water absorption of AAS mortars was significantly reduced by $74.42 \%$ to $97.79 \%$. This is consistent with the results of other studies [18].

In addition, the water absorption rate of the $\mathrm{O} 200$ group with a coating dosage of $200 \mathrm{~g} / \mathrm{m}^{2}$ was the lowest under onelayer coating and the water absorption rate of AAS mortars under two-layer coating were all lower than that of one-layer coating with an identical coating dosage of silane. This phenomenon was caused by the surface of the mortar being saturated with too much silane, which cannot penetrate into the interior of the mortar to cause loss. And the one-layer coating compared with the two-layer coating with an identical dosage of silane was easily saturated on the surface, hindering further penetration into the interior of the mortar. The results show that the effect of two-layer coating on the further action of mortar and silane was better than that of one-layer coating.

Moreover, the second coating makes up for the defect because the first coating of silane with high permeability penetrated the mortar without fully interaction with the surface mortar.

3.2. Contact Angle. Figure 8 presents the contact angle test results of each group of AAS mortars. The contact angle values of each mortar specimen are marked in Figure 8. It can be clearly observed that the contact angle of the ordinary AAS mortar was $36^{\circ}$ because of its hydrophilic property, showing a good wetting effect. Through surface impregnation by silane, the contact angle of AAS mortars was significantly increased by $80^{\circ}$ from $36^{\circ}$ to $116^{\circ}$, which converts the surface property of AAS mortars from strong hydrophilic to hydrophobic. The improvement in contact angle is caused by the reduction in surface tension after 


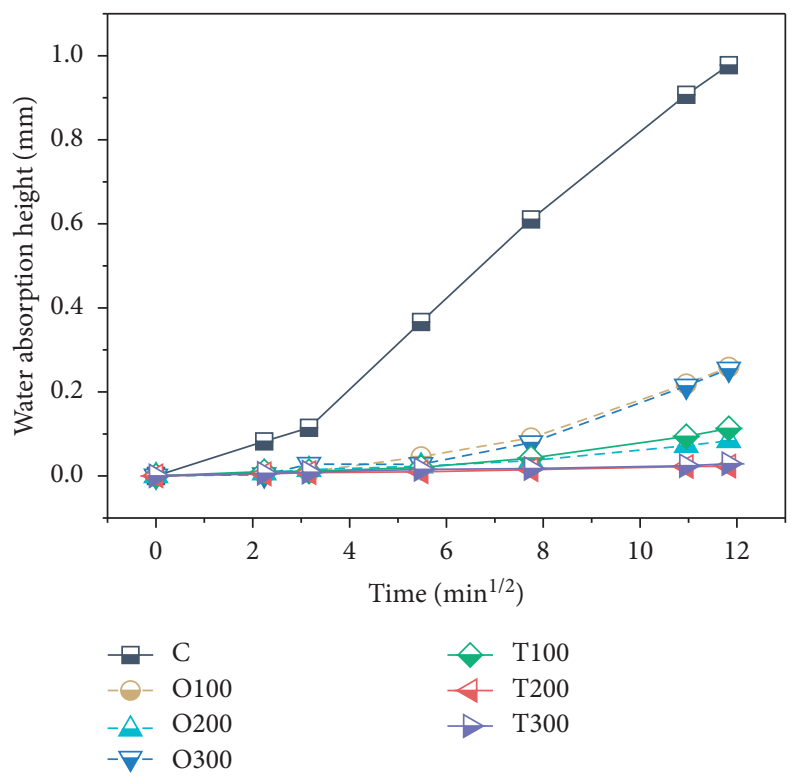

FigURE 6: Water absorption height of sample under different coating methods.

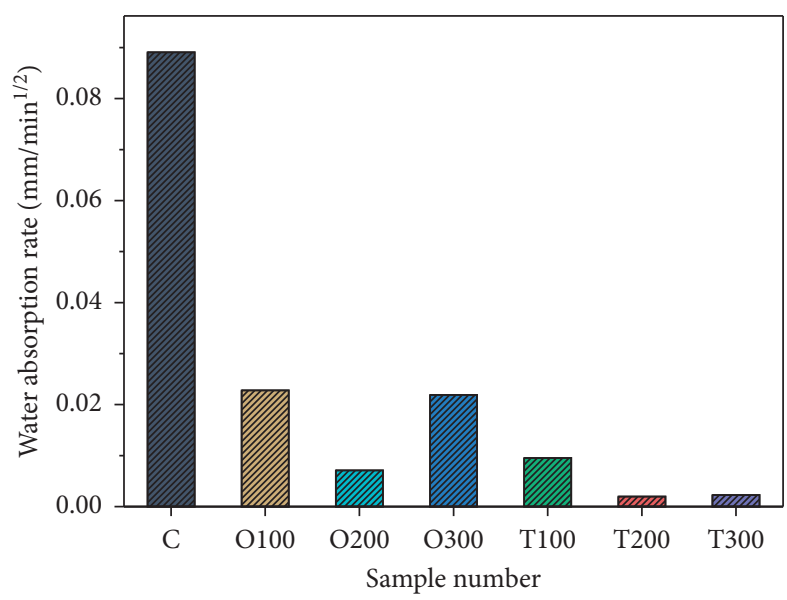

FiguRE 7: Water absorption rate of samples under different coating methods.

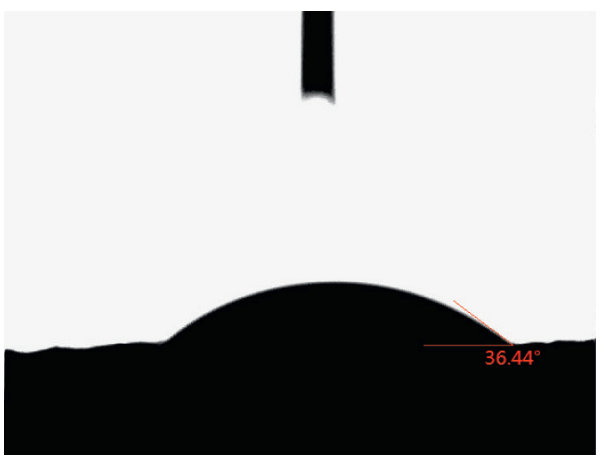

(a)

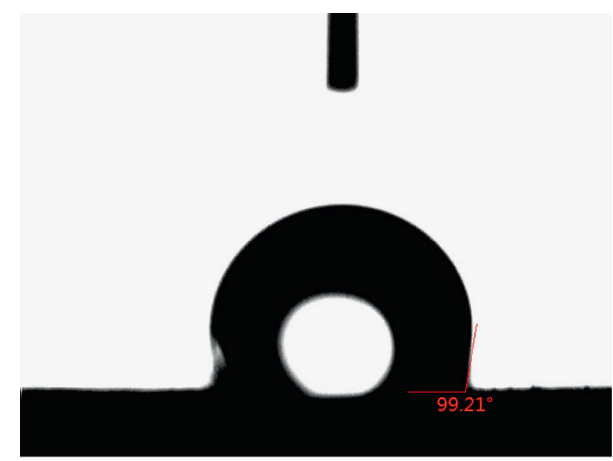

(b)

Figure 8: Continued. 


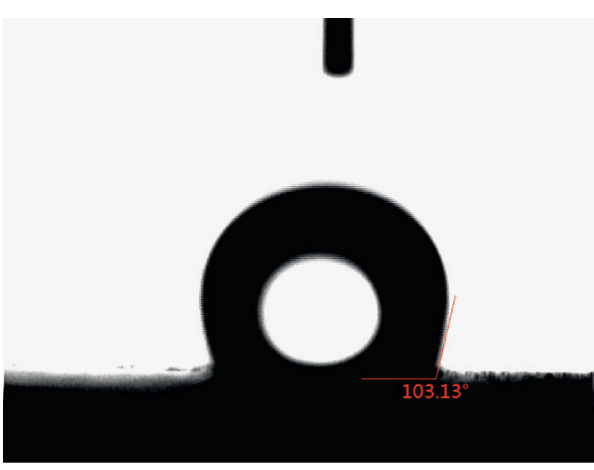

(c)

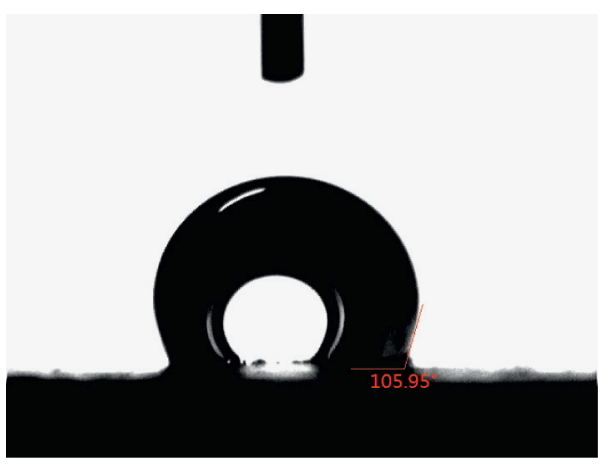

(e)

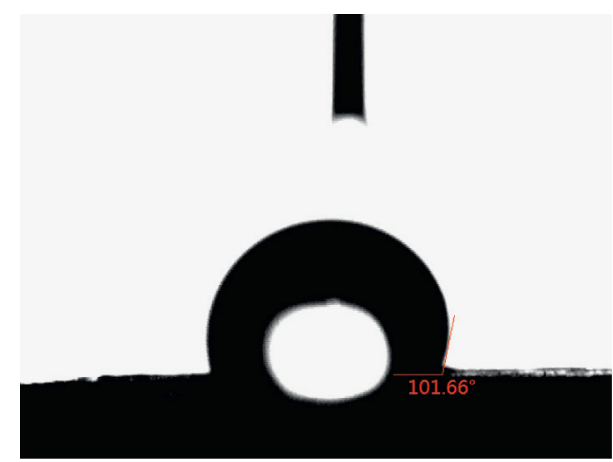

(d)

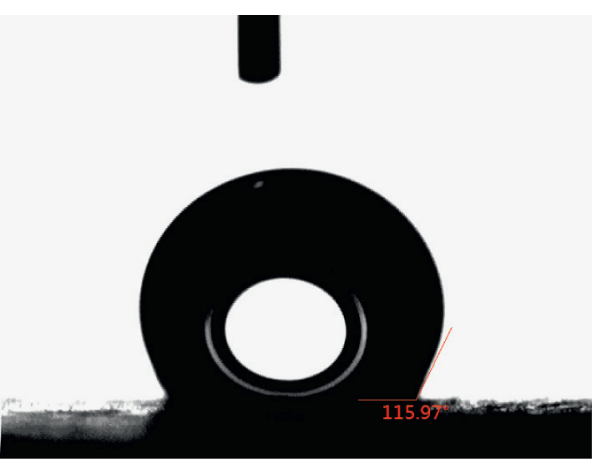

(f)

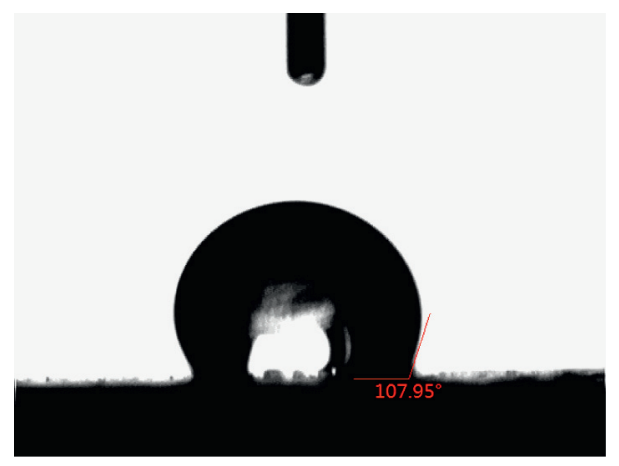

(g)

FIgure 8: Contact angle of alkali-activated slag mortar. (a) C; (b) O100; (c) O200; (d) O300; (e) T100; (f) T200; (g) T300.

silane coating, resulting in a reduction in the migration rate of water into AAS mortar [29, 30]. This promoted hydrophobic is beneficial for achieving better protection of the AAS mortars. It is worthwhile mentioning that the contact angle of the surface first increased and then decreased with the increasing coating dosage, regardless of one-layer coating or two-layer coating. This is attributed to excessive silane damage to the protection network-like hydrophobic film.

Moreover, the two-layer coating showed more excellent hydrophobic properties compared to the one-layer coating. The contact angle of the AAS mortar surface with the twolayer coating was quite larger than that of the one-layer coating with an identical coating dosage, showing better hydrophobic performance. Similarly, the contact angle obtained by the two-layer coating was the largest at a coating dosage of $200 \mathrm{~g} / \mathrm{m}^{2}$. This is consistent with the results of water absorption. This is attributed to the two-layer coating making up for the shortcomings of the one-layer coating that the silane penetrated deep inside the mortar without fully reacting with the surface mortar. The ethyl $\left(-\mathrm{CH}_{2} \mathrm{CH}_{3}\right)$ group in the silane reacted with the AAS mortar to form a network-like hydrophobic film with hydrophobic properties in the impregnated zone. In particular, too much silane may damage the formed hydrophobic film, causing a slight decrease in the contact angle.

3.3. Penetration Depth. The penetration depths of silane impregnation on the AAS mortar are illustrated in Figure 9. It can be observed that the penetration depth of silane progressively increased with the increase in the coating dosage of both one-layer and two-layer coatings. The progressive increase in penetration depth was owing to the fact 


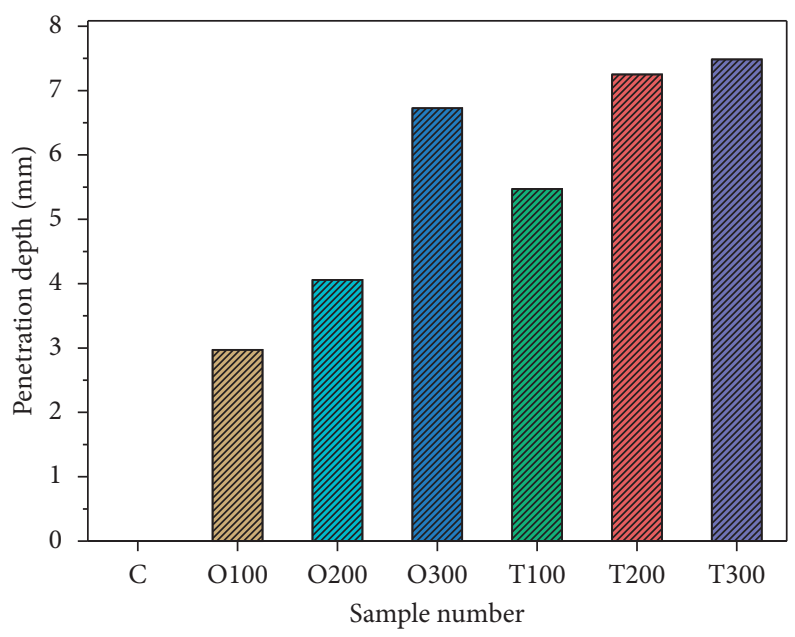

Figure 9: Penetration depth of silane into mortar.

that the main component of the selected silane was isobutyltriethoxysilane, which has good permeability due to its short molecular structure. This is in agreement with the finding of Zhu et al. [17].

Moreover, the penetration depth of the two-layer coating was greater than the one-layer coating with an identical coating dosage. The penetration depth of one-layer coating and two-layer coating at the coating dosage of $100 \mathrm{~g} / \mathrm{m}^{2}$ was $2.8 \mathrm{~mm}$ and $5.2 \mathrm{~mm}$, respectively. This phenomenon was mainly attributed to the fact that the dry surface of mortar was easy to be saturated by silane impregnation during one coating, resulting in the loss of silane, thus affecting the penetration depth of silane. The two-layer coating was equivalent to a reduction of the single coating amount. Moreover, the surface originally wetted by silane became dry during the second coating at an interval of $6 \mathrm{~h}$. This is conducive to the penetration of silane, avoiding the influence of silane penetration caused by the saturation of mortar capillary pores coated with a large number of silane in a short time. Note that a little increment in the penetration depth was observed in the T200 and T300 groups, suggesting excess silane was detrimental to the increase in penetration depth. This phenomenon is caused by the formed hydrophobic film of silane that obstructed the penetration of subsequent silane. On the other hand, the total coating dosage of more than $200 \mathrm{~g} / \mathrm{m}^{2}$ tends to saturate the treated surface of the AAS mortar.

\subsection{Morphology and Mineralogical Composition}

3.4.1. SEM. Figure 10 displays the SEM image of all samples cured to 28 days with different coating methods and coating dosages. As can be seen from Figure 10, no obvious difference is found in the microstructure of all the experimental groups compared to the control group (C). And there is no clear difference with respect to the density of mortar and the porosity after protective treatment [31]. Moreover, no new hydration products were found after silane protection. Compared to that of the control group without surface impregnation, a lamellar structure was formed on the inner surface of the AAS mortar impregnated with silane. This phenomenon was a consequence of the test AAS mortars being cured for 28 days with a good hydration process. And the hydrolytic condensation reaction of silane formed Si-O$\mathrm{CH}_{2} \mathrm{CH}_{3}$ bonding with the mortar and formed a hydrophobic film in the impregnated zone of the mortar without affecting the hydration products and microstructure of the mortar. In addition, nonpolar groups were introduced into capillary pores lining up toward the outside, which reduced the surface free energy of pores. Thus, the excellent hydrophobic property of AAS mortars and a good protective effect were obtained.

3.4.2. XRD. Figure 11 shows the mineral phase composition of all mortars at 28 days. Similar XRD patterns between the experimental group and the control group were obtained. 6 kinds of minerals were determined according to the standard JCPDS documents and reference materials. The main phases of AAS mortars for 28 days were quartz, C-S-H, C-A-S-H, hydrotalcite, tobermorite, and calcite in the control group.

It can be seen from Figure 11 that the main hydration products of mortar were not affected after surface impregnation curing for 7 days, which is greatly in agreement with the observations of Xue et al. [32]. This phenomenon is caused by the hydrophobic film being formed on the surface of AAS mortar by the hydrolysis condensation of silane and forming $\mathrm{Si}-\mathrm{O}-\mathrm{CH}_{2} \mathrm{CH}_{3}$ bond in the mortar without introducing extra hydration products. On the other hand, the object of protective treatment was the AAS mortars cured for 28 days fully hydrated. In addition, fine aggregates (sand) incorporated into AAS mortars were accounted for the silica phase in the specimen and calcite may be caused by carbonization during sample preparation.

3.4.3. FT-IR. Figure 12 shows the FT-IR spectrum of alkaliactivated slag mortar at the wavelength of $4000 \mathrm{~cm}^{-1}-400 \mathrm{~cm}^{-1}$ at 28 days with different coating methods and coating dosages. It is clearly seen that there are remarkably two different absorption peaks of $2926 \mathrm{~cm}^{-1}$ and 

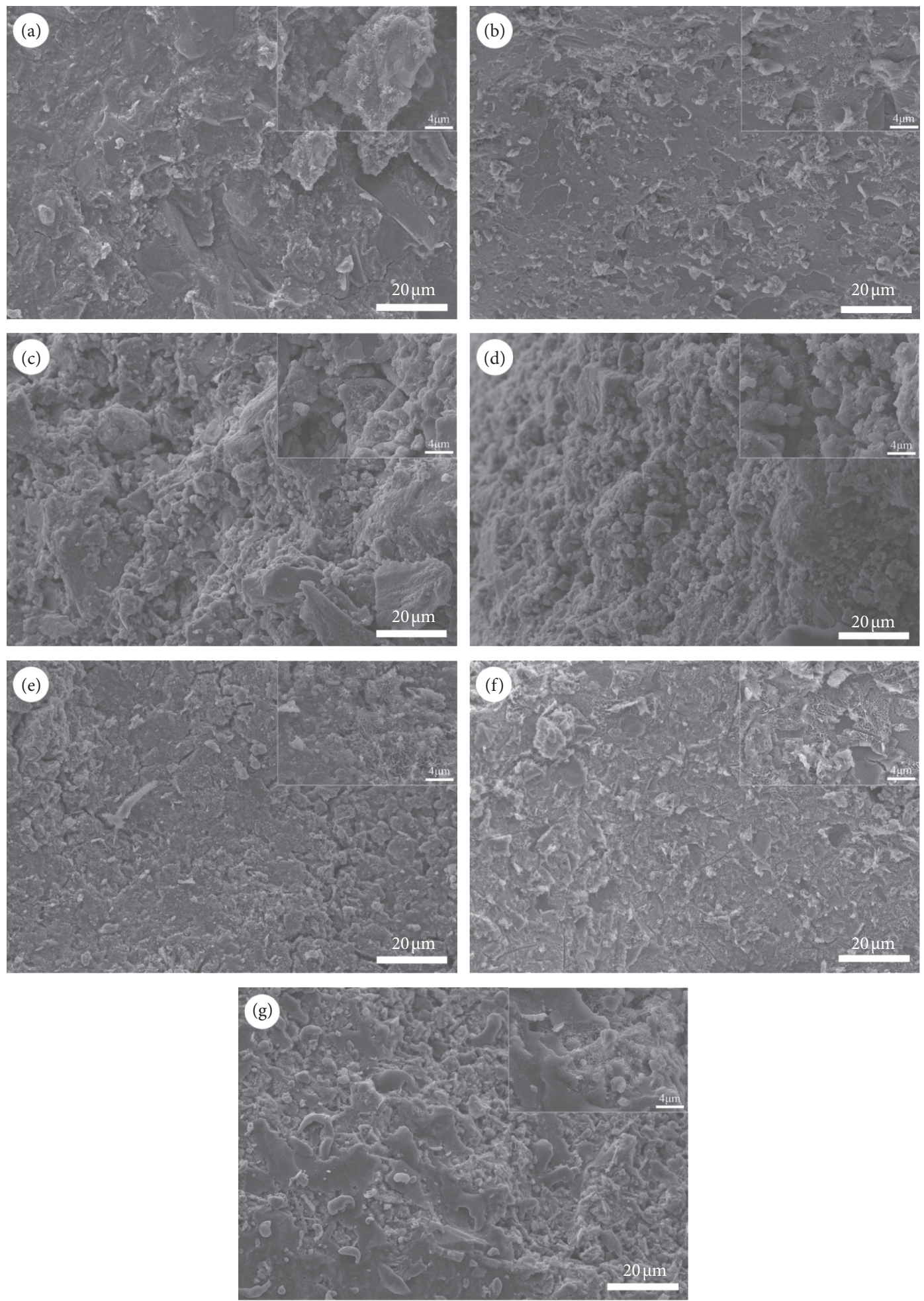

Figure 10: SEM image of alkali-activated mortar in various coating methods. (a) C; (b) O100; (c) O200; (d) O300; (e) T100; (f) T200; (g) T300.

$2856 \mathrm{~cm}^{-1}$ between the treated and untreated AAS mortars. These are related to the $\mathrm{C}-\mathrm{H}$ bond stretching vibration of the ethyl $\left(-\mathrm{CH}_{2} \mathrm{CH}_{3}\right)$ group in isobutyltriethoxysilane [33]. These two absorption peaks indicate that silane has successfully acted on the AAS mortars and formed a hydrophobic film inside the pores near the zone impregnated by silane.

The peak at $1654 \mathrm{~cm}^{-1}$ is the $\mathrm{H}-\mathrm{OH}$ bending vibration peak of slag. Bands at about $1430 \mathrm{~cm}^{-1}, 956 \mathrm{~cm}^{-1}, 897 \mathrm{~cm}^{-1}$, and $670 \mathrm{~cm}^{-1}$ are related to the characteristic absorption 

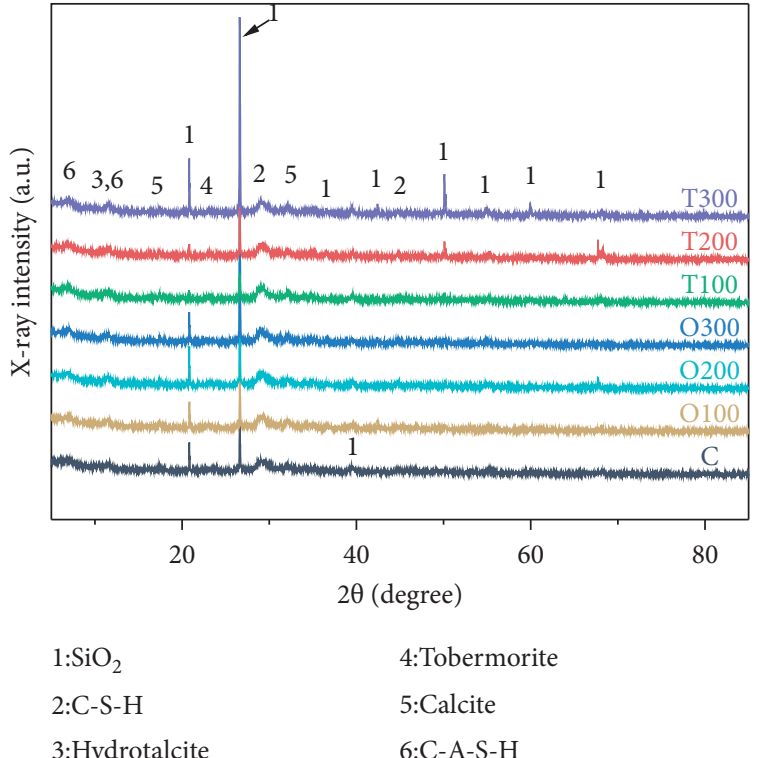

Figure 11: XRD patterns of $28 \mathrm{~d}$ pastes.

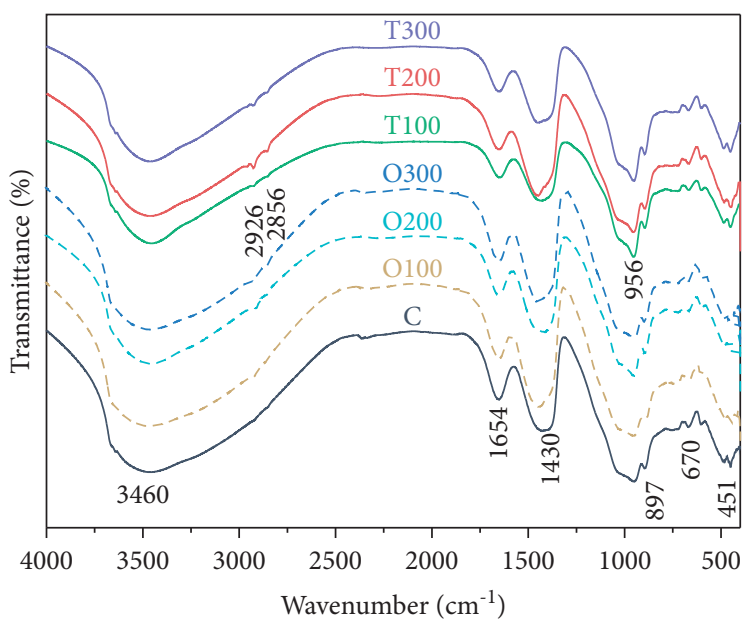

FIGURE 12: FT-IR spectra of mortar under different treatments.

peaks of C-S-H $[34,35]$. In addition, the vibration band near $1430 \mathrm{~cm}^{-1}$ may also be caused by calcium carbonate [36]. The peak at $451 \mathrm{~cm}^{-1}$ corresponds to the Si-O band in silica. The band at $3460 \mathrm{~cm}^{-1}$ is related to the vibration absorption peak of free $-\mathrm{OH}$ owing to the alkaline of the AAS mortar.

\section{Conclusion}

This paper investigated the effects of silane impregnation on the protection of AAS mortars. According to the above experimental results and discussions, the following conclusions can be drawn:

(1) Surface impregnation of AAS mortars was efficient at increasing contact angle, which transformed the surface property of the AAS mortar from hydrophilic to hydrophobic. And the water absorption was successfully suppressed by its surface hydrophobicity after surface silane impregnation. The penetration depth of silane increased with increasing silane dosage. And the penetration depth of silane on AAS mortars under two-layer coating was higher than that under one-layer coating.

(2) The optimal coating method of two-layer and the optimal coating dosage of $200 \mathrm{~g} / \mathrm{m}^{2}$ were determined by minimum water absorption and maximum contact angle.

(3) The surface impregnation of silane did not affect the microstructure of the AAS mortar and the formation of hydration products. It is mainly attributed to the ethyl $\left(-\mathrm{CH}_{2}-\mathrm{CH}_{3}\right)$ group of silane interacting with the AAS mortar substrate, forming a net hydrophobic membrane, thus improving the durability of AAS mortars.

\section{Data Availability}

The data used to support the findings of this study are available from the corresponding author upon request.

\section{Conflicts of Interest}

The authors declare that they have no conflicts of interest regarding the publication of this paper.

\section{Acknowledgments}

This study was funded by the National Natural Science Foundation of China (52008003), Anhui Province Science and Technology Plan Project of Housing Urban-rural Construction (2020-YF12 and 2020-YF14), Key Research and Development Program Project of Anhui Province (201904a07020081), and Nature Science Foundation of Anhui (1908085QE213).

\section{References}

[1] A. Sedaghatdoost, K. Behfarnia, M. Bayati, and M. s. Vaezi, "Influence of recycled concrete aggregates on alkali-activated slag mortar exposed to elevated temperatures," Journal of Building Engineering, vol. 26, Article ID 100871, 2019.

[2] S. M. Zabihi and H. R. Tavakoli, "Evaluation of monomer ratio on performance of GGBFS-RHA alkali-activated concretes," Construction and Building Materials, vol. 208, pp. 326-332, 2019.

[3] C. S. Thunuguntla and T. D. Gunneswara Rao, "Effect of mix design parameters on mechanical and durability properties of alkali activated slag concrete," Construction and Building Materials, vol. 193, pp. 173-188, 2018.

[4] B. Słomka-Słupik, J. Podwórny, and M. Staszuk, "Corrosion of cement pastes made of CEM I and CEM III/A caused by a saturated water solution of ammonium chloride after 4 and 25-days of aggressive immersion," Construction and Building Materials, vol. 170, pp. 279-289, 2018.

[5] K. Kobayashi, M. Suzuki, L. A. Dung, H.-d. Yun, and K. Rokugo, "The effects of PE and PVA fiber and water cement ratio on chloride penetration and rebar corrosion protection performance of cracked SHCC," Construction and Building Materials, vol. 178, pp. 372-383, 2018. 
[6] S. Ghorbani, I. Taji, M. Tavakkolizadeh, A. Davodi, and J. De Brito, "Improving corrosion resistance of steel rebars in concrete with marble and granite waste dust as partial cement replacement," Construction and Building Materials, vol. 185, pp. 110-119, 2018.

[7] J. He, Q. Gao, Y. Wu, J. He, and X. Pu, "Study on improvement of carbonation resistance of alkali-activated slag concrete," Construction and Building Materials, vol. 176, pp. 60-67, 2018.

[8] C. Gong, L. Jianzhong, C. Cuicui, L. Changfeng, and S. Liang, "Study on silane impregnation for protection of high performance concrete," Procedia Engineering, vol. 27, pp. 301307, 2012.

[9] J.-G. Dai, Y. Akira, F. H. Wittmann, H. Yokota, and P. Zhang, "Water repellent surface impregnation for extension of service life of reinforced concrete structures in marine environments: the role of cracks," Cement and Concrete Composites, vol. 32, no. 2, pp. 101-109, 2010.

[10] X. Xue, Y. Li, Z. Yang et al., "A systematic investigation of the waterproofing performance and chloride resistance of a selfdeveloped waterborne silane-based hydrophobic agent for mortar and concrete," Construction and Building Materials, vol. 155, pp. 939-946, 2017.

[11] M. Ibrahim, A. S. Al-Gahtani, M. Maslehuddin, and A. A. Almusallam, "Effectiveness of concrete surface treatmentmaterials in reducing chloride-induced reinforcement corrosion," Construction and Building Materials, vol. 11, no. 7, pp. 443-451, 1997.

[12] M. Horgnies and J. J. Chen, "Superhydrophobic concrete surfaces with integrated microtexture," Cement and Concrete Composites, vol. 52, pp. 81-90, 2014.

[13] P. Scarfato, L. Di Maio, M. L. Fariello, P. Russo, and L. Incarnato, "Preparation and evaluation of polymer/clay nanocomposite surface treatments for concrete durability enhancement," Cement and Concrete Composites, vol. 34, no. 3, pp. 297-305, 2012.

[14] E. Franzoni, B. Pigino, and C. Pistolesi, "Ethyl silicate for surface protection of concrete: performance in comparison with other inorganic surface treatments," Cement and Concrete Composites, vol. 44, no. 11, pp. 69-76, 2013.

[15] D. W. Pfeifer and M. J. Scali, Concrete Sealers for Protection of Bridge Structures, National Cooperative Highway Research Program Report, Washtngton, NY, USA, 1981.

[16] C. Christodoulou, C. I. Goodier, S. A. Austin, J. Webb, and G. K. Glass, "Long-term performance of surface impregnation of reinforced concrete structures with silane," Construction and Building Materials, vol. 48, pp. 708-716, 2013.

[17] Y.-G. Zhu, S.-C. Kou, C.-S. Poon, J.-G. Dai, and Q.-Y. Li, "Influence of silane-based water repellent on the durability properties of recycled aggregate concrete," Cement and Concrete Composites, vol. 35, no. 1, pp. 32-38, 2013.

[18] M. H. F. Medeiros and P. Helene, "Surface treatment of reinforced concrete in marine environment: influence on chloride diffusion coefficient and capillary water absorption," Construction and Building Materials, vol. 23, no. 3, pp. 1476-1484, 2009.

[19] X.-M. Kong, H. Liu, Z.-B. Lu, and D.-M. Wang, "The influence of silanes on hydration and strength development of cementitious systems," Cement and Concrete Research, vol. 67, pp. 168-178, 2015.

[20] K. Namoulniara, P.-Y. Mahieux, J. Lux, A. Aït-Mokhtar, and P. Turcry, "Efficiency of water repellent surface treatment: experiments on low performance concrete and numerical investigation with pore network model," Construction and Building Materials, vol. 227, Article ID 116638, 2019.

[21] B. Sudbrink, M. Khanzadeh Moradllo, Q. Hu et al., "Imaging the presence of silane coatings in concrete with micro X-ray fluorescence," Cement and Concrete Research, vol. 92, pp. 121-127, 2017.

[22] Z. Liu and W. Hansen, "Effect of hydrophobic surface treatment on freeze-thaw durability of concrete," Cement and Concrete Composites, vol. 69, pp. 49-60, 2016.

[23] Y. Cai, P. Hou, C. Duan et al., "The use of tetraethyl orthosilicate silane (TEOS) for surface-treatment of hardened cement-based materials: a comparison study with normal treatment agents," Construction and Building Materials, vol. 117, pp. 144-151, 2016.

[24] F. Tittarelli and G. Moriconi, "Comparison between surface and bulk hydrophobic treatment against corrosion of galvanized reinforcing steel in concrete," Cement and Concrete Research, vol. 41, no. 6, pp. 609-614, 2011.

[25] Gb/T18046-2017, Ground Granulated Blast Furnace Slag Used for Cement, Mortar and Concrete, Standardization Admination of the Peoples's Republic of China, SAC, China, 2017.

[26] I.-A. Ciobotaru, I. Maior, D.-I. Vaireanu, A. Cojocaru, S. Caprarescu, and I.-E. Ciobotaru, "The determination of the optimum hydrolysis time for silane films deposition," Applied Surface Science, vol. 371, pp. 275-280, 2016.

[27] Jtj275-2000, Corrosion Prevention Technical Specifications for Concrete Structures of Marine Harbour Engineering, Standardization Admination of the Peoples's Republic of China, SAC, China, 2017.

[28] J. Li, P. Chen, H. Cai et al., "Performance of rubber mortars containing silica coated rubber," Materiales de Construcción, vol. 71, no. 342, p. e244, 2021.

[29] S. Li, W. Zhang, J. Liu et al., "Protective mechanism of silane on concrete upon marine exposure," Coatings, vol. 9, no. 9, p. 558, 2019.

[30] W. Zhang, S. Li, D. Hou et al., "Study on unsaturated transport of cement-based silane sol coating materials," Coatings, vol. 9, no. 7, p. 427, 2019.

[31] Y. Zhang, S. Li, W. Zhang et al., "Preparation and mechanism of graphene oxide/isobutyltriethoxysilane composite emulsion and its effects on waterproof performance of concrete," Construction and Building Materials, vol. 208, pp. 343-349, 2019.

[32] X. Xue, Y.-L. Liu, J.-G. Dai, C.-S. Poon, W.-D. Zhang, and P. Zhang, "Inhibiting efflorescence formation on fly ash-based geopolymer via silane surface modification," Cement and Concrete Composites, vol. 94, pp. 43-52, 2018.

[33] C. Zhang, Z. Hu, H. Zhu, X. Wang, and J. Gao, "Effects of silane on reaction process and microstructure of metakaolinbased geopolymer composites," Journal of Building Engineering, vol. 32, Article ID 101695, 2020.

[34] N. Li, N. Farzadnia, and C. Shi, "Microstructural changes in alkali-activated slag mortars induced by accelerated carbonation," Cement and Concrete Research, vol. 100, pp. 214-226, 2017.

[35] S. A. Bernal, R. M. De Gutierrez, J. L. Provis, and V. Rose, "Effect of silicate modulus and metakaolin incorporation on the carbonation of alkali silicate-activated slags," Cement and Concrete Research, vol. 40, no. 6, pp. 898-907, 2010.

[36] M. Sato and S. Matsuda, "Structure of vaterite and infrared spectra," Ztschrift Für Kristallographie, vol. 129, no. 5-6, pp. 405-410, 1969. 